\title{
Effect of rice mash on the quality characteristics of strawberry jam
}

\author{
Mi Jin Kim, Jin Sook Kim*, Young Eun Chang \\ Department of Agro-Food Resources, National Institute of Agricultural Science, Rural Development Administration, \\ Wanju 55365, Korea
}

\section{쌀당화액 첨가량에 따른 딸기잼의 품질특성}

\author{
김미진 · 김진숙* · 장영은 \\ 농촌진흥청 국립농업과학원 농식품자원부
}

\begin{abstract}
This study investigated the physical, textural, and sensory properties of strawberry jam with different amounts $(0 \%, 14 \%$, and $21 \%)$ of added rice mash. The soluble solids, $\mathrm{pH}$, and total acidity values of the samples were found to be in the range of $53.00 \sim 65.33{ }^{\circ} \mathrm{Brix}, 4.11 \sim 4.20$ and $0.66 \sim 0.80 \%$, respectively. Soluble solids and total acidity decreased significantly as the amount of rice mash was increased. The L-value, a-value, and b-value increased on increasing the amount of rice mash $(\mathrm{p}<0.05)$. The glucose contents of the samples ranged from $3.86 \mathrm{~g}$ to 4.13 g. The fructose, sucrose, and maltose contents significantly decreased $(p<0.05)$. The organic acid content was measured and it was found that, oxalic acid was not in the control sample $(0 \%$ rice mash). As the rice mash content was increased, the succinic acid content also increased $(p<0.05)$, but the citric acid content decreased significantly $(p<0.05)$. In the sensory evaluation, strawberry jam with rice mash showed superior spreading property than that of the control sample. Strawberry jam with $0 \%$ rice mash had the highest color and taste score. For the overall acceptability, strawberry jams with $0 \%$ and, $14 \%$ of rice mash were preferable to that with $21 \%$.
\end{abstract}

Key words : rice, koji, rice mash, strawberry, jam

\section{서 론}

딸기(Fragaria ananassa Duch.)는 장미과에 속하는 다년 초로 색과 향이 우수하고 신맛과 단맛의 조화로 생식하는 것 이외에 잼, 젤리 등의 가공품 소재로 이용하고 있으며 그 종류도 다양화되고 있다(1). 딸기는 품종에 따라 성분 함량이 다르나 vitamin C, quercetin, ferulic acid, caffeic acid, flavanol류 및 안토시아닌 등 다양한 항산화 물질을 갖고 있다(2). 또한 딸기의 안토시아닌 화합물은 산소라디칼 제 거, 산화적 스트레스에 의한 세포변형 억제 등의 항산화 효능이 뛰어나며(3), 유기산과 당분이 많아 맛이 좋을 뿐만

*Corresponding author. E-mail : preetyjs@korea.kr Phone : 82-63-238-3555, Fax : 82-63-238-3842

Received 3 September 2015; Revised 15 October 2015; Accepted 26 October 2015.

Copyright (c) The Korean Society of Food Preservation. All rights reserved.
아니라 철분, 칼륨의 함유량이 많아 혈액순환에 도움이 되 는 것으로 알려져 있다(4). 최근 산업사회의 발달과 생활수 준이 향상됨에 따라 현대인들의 식생활이 변화되어 빵과 같은 편의식품의 소비가 증가하고 있으며, 이와 더불어 잼 의 소비도 증가하였고 그 종류도 다양하다(5). 일반적으로 잼은 단맛, 보존성을 증가시키기 위해 다량의 설탕을 첨가 하여 만드는 가공식품으로 식품공전에서는 '잼류는 과일류 또는 채소류를 당류 등과 함께 젤리화 또는 시럽화한 것으 로 잼, 마멀레이드 등을 말한다'라고 정의되어 있다(6). 잼 은 과실을 펄프상태로 만들어 당분, 구연산, 펙틴을 첨가하 여 가열 농축하여 제조하는데 각각의 함량이 $60 ~ 65 \%$, $0.3 \%, 1 \sim 1.5 \%$ 일 때 젤리화가 가장 잘 일어나는 것으로 알려 져 있다 $(7,8)$. 잼은 최대 $70 \%$ 수준까지의 설탕 첨가로 당도 를 높여 미생물의 성장을 억제시켜 방부성, 저장성을 증대 시키는 저장형 식품이었으나 현재 소비자의 건강지향 소비 트랜드 실정에서 설탕의 다량 섭취는 선호하지 않는다. 또 한 당 과잉섭취로 인한 충치, 비만, 당느병 등 성인병의 
원인이 될 수 있어 기피하고 있는 추세로 이에 따른 새로운 형태의 잼의 개발이 필요하다(9). 이러한 소비자의 옥구를 충족하기 위해 잼의 저당성(10-13), 기능성(14-17) 등에 관 한 다양한 연구가 시행되었으나, 발효 소재를 이용하여 잼 을 제조함으로서 잼의 저당화와 기능성 향상을 시도한 연구 는 미비한 실정이다.

우리나라의 전통적인 누룩의 유용 미생물 중의 하나인 Aspergillus kawachii는 누룩(koji)을 제조하기가 유용할 뿐 만 아니라 유기산과 당화효소를 잘 생산하여 술덧의 $\mathrm{pH}$ 가 안전한 산성을 유지하는데 이점이 있다고 보고되었다(18). 쌀누룩(rice koji)을 발효제로 하여 생성한 당화액(rice mash) 을 조리수(물) 대신에 당화액을 사용한 당화 딸기죽은 무첨 가구에 비해 영양-기능성이 향상되었다고 하였다(19). Asp. kawachii와 Asp. oryzae의 미생물을 함유하는 rice koji로부 터 쌀전분을 분해하여 생성된 rice mash는 품질이 다르다 (20). 즉 Asp. kawachii는 자연당과 유기산을 함유하고 Asp. oryzae는 자연당을 함유하게 하는 발효제 역할을 하므로 이의 특성을 이용하여 다양한 식품원료로 사용할 수 있을 것으로 보고하였다(20).

따라서 본 연구에서는 Asp. kawachii를 갖는 rice koji를 발효제로 이용해서 쌀의 전분을 분해하여 유기산과 당을 갖는 쌀당화액(rice mash)를 조제하여 딸기잼 제조 원료로 활용하였다. 잼의 주원료인 딸기와 설탕 이외에 rice mash의 첨가량을 달리하여 잼을 제조하고 그 품질특성을 조사하여 저당도 잼 제조를 위한 기초자료를 제공하고자 한다.

\section{재료 및 방법}

\section{실험재료}

냉동 딸기는 2012년에 수확한 설향 품종으로 세척 후 바로 냉동한 제품(하늘땅냉동조합법인, Nonsan, Korea)을 사용하였다. Rice mash는 $\mathrm{Kim}$ 등(20)의 방법에 준하여 호화 쌀전분(밥)에 발효제로서 Asp. kawachii의 rice koji(Dongsan Co., Yongin, Korea)를 넣고 $60^{\circ} \mathrm{C}$ 에서 6시간 당화하여 제조 하였고 $75^{\circ} \mathrm{C}$ 에서 15 분간 가열처리하여 사용하였다. 이때 사용한 rice mash의 당도, 산도, 유리당, 유기산 등의 품질은 보고되었다(20). 백설탕(CJ, Incheon, Korea)은 시중에서 구 입하여 사용하였다.

\section{당화 딸기잼 제조}

당화 딸기잼은 원료 배합비는 예비실험을 통하여 Table 1 과 같이, 딸기 $70 \%$ 와 설탕 $30 \%$ 의 총무게 $(100 \%)$ 대비 쌀당 화액(rice mash)을 $14 \%, 21 \%$ 를 처리수준으로 정하였다. 냉 동 딸기는 실온에서 해동한 후 블랜더(HR1378, Philips, Kamtner, Slovenia)에 1분 정도 갈아 퓨레 형태로 만들었다. 본 연구의 분석 시료인 딸기잼은 딸기 퓨레를 강한 불로
가열(전기렌지, EP-701, 유로팬저머니, Seoul, Korea)하다 가 끓으면 각각 설탕, 당화액을 2회 나누어 넣고 냄비 바닥 에 내용물이 들러붙지 않도록 저어주면서 제조하였으며, 잼의 완성점은 수분함량 $45 \%$ 로 맞추었다,

Table 1. Formula for strawberry jam with different levels of added rice mash

\begin{tabular}{cccc}
\hline \multirow{2}{*}{ Sample code $^{1)}$} & \multicolumn{3}{c}{ Ingredients (\%) } \\
\cline { 2 - 4 } & Strawberry & Sugar & Rice mash \\
\hline SJ0 (control) & 70 & 30 & 0 \\
SJ14 & 70 & 30 & 14 \\
SJ21 & 70 & 30 & 21 \\
\hline
\end{tabular}

${ }^{1)}$ SJ0, strawberry jam added with no rice mash; SJ14, strawberty jam added with rice mash 14\%; SJ21, strawberty jam added with rice mash $21 \%$.

\section{당도, $\mathrm{pH}$ 및 총산도 측정}

당도는 굴절당도계(PAL-3, Atago Co., Ltd., Tokyo, $\mathrm{Japan}$ )를 이용하였고 3회 반복 측정하여 평균값을 가용성 고형분 함량( $\left.{ }^{\circ} \mathrm{Brix}\right)$ 으로 표시하였다. $\mathrm{pH}$ 는 $\mathrm{pH}$ meter(Orion 4 STAR, Thermo Scientific, Beverly, MA, USA)를 사용하여 3 회 반복 측정하였다. 총산도는 시료액 $10 \mathrm{~mL}$ 에 증류수 $40 \mathrm{~mL}$ 를 가하여 희석한 후 $\mathrm{pH}$ meter로 3회 반복 측정하였으 며 시료액의 $\mathrm{pH}$ 가 8.3 까지 도달하는데 필요한 $\mathrm{NaOH}$ 소비 량 $(\mathrm{mL})$ 을 citric acid 함량 $(\%)$ 으로 환산하여 나타내었다.

\section{색도 측정}

색도는 색차계(CR-300, Minolta Co., Tokyo, Japan)를 사 용하여 일정량씩 취한 각 시료의 $\mathrm{L}(\mathrm{Lightness}), \mathrm{a}$ (redness) 및 $\mathrm{b}$ (yelloweness)를 3회 반복 측정하여 나타내었다. 이 때 사용된 표준백색판의 $\mathrm{L}, \mathrm{a}$ 및 $\mathrm{b}$ 값은 각각 $95.72,-0.18$, 2.91 이었다.

\section{유리당 함량 측정}

유리당은 시료 $10 \mathrm{~g}$ 에 증류수 $90 \mathrm{~mL}$ 를 가하여 homogenizer(Ultra-Turrax T25, IKA Laboretechnik Co., Staufen, Germany)로 30초간 균질화하고 원심분리(15,000 $\mathrm{rpm}, 15$ 분)한 후 Whatman No. 2 여과지(Whatman International Ltd., Maidstone, UK)를 이용하여 상등액을 여 과하고 $100 \mathrm{~mL}$ 로 정용하였다. 추출물은 $0.2 \mu \mathrm{m}$ membrane filter로 여과하여 사용하였고 HPLC(Agilent Technologies 1200 series, Palo Alto, CA, USA)로 분석하였다. 분석 시 detector는 ELSD를 이용하였고, column은 Shodex asahipak NP2P-5-4E(5 m, 4.6×250 mm, Tokyo, Japan)를, 이동상은 $70 \%$ acetonitrile을 $1.2 \mathrm{~mL} / \mathrm{min}$ 로 흘려주었고, $5 \mu \mathrm{L}$ 를 주입하 여 분석하였다. 표준물질로는 fructose, glucose, sucrose 및 maltose(Sigma chemical Co., St Louis, MO, USA)을 사용하 였다. 


\section{유기산 함량 측정}

유기산 함량은 oxalic acid, citric acid, malic acid 및 succinic acid를 표준물질로 organic acid kit(Supelco, Bellefonte, PA, USA)를 사용하였다. 분석용 추출물은 시료 $10 \mathrm{~g}$ 에 증류수 $90 \mathrm{~mL}$ 를 가하여 homogenizer로 30 초간 균질 화하고 원심분리( $15,000 \mathrm{rpm}, 15$ 분)한 후 Whatman No. 2 여과지를 이용하여 상등액을 여과하고 $100 \mathrm{~mL}$ 로 정용하였 다. 추출물은 HPLC(Agilent Technologies 1200 series, Palo Alto, CA, USA)로 분석하였고, 칼럼은 aminex HPX-87H ion exclusion column $(7.8 \times 300 \mathrm{~mm}$, Bio-Rad, Hercules, CA, USA)를 사용하였다. 검출기는 UV detector를 이용하였으 며, 이동상은 $0.008 \mathrm{~N}$ sulfuric acid 용액을 $0.6 \mathrm{~mL} / \mathrm{min}$ 로 흘려주며 시료는 $10 \mu \mathrm{L}$ 를 주입하여 분석하였다.

\section{관능검사}

관능검사는 국립농업과학원 식품부 연구원 15 명을 패널 로 선정하여 개별 칸막이가 설치된 검사대에서 실시하였 다. 시료는 일정량 $(20 \mathrm{~g})$ 씩 담아 물과 식빵(우유)을 함께 제 공하였으며 난수표를 이용하여 3 자리 숫자를 사용하여 평가하도록 하였다. 관능검사 항목은 색, 향, 맛, 질감, 스프 레드 정도, 전반적 기호도 등의 특성을 기호도 검사로 실시 하였고 다른 시료를 평가할 경우에는 물로 입을 헹구게 하였고 스프레드 정도 테스트는 식빵을 사용하였다. 이때 점수는 9점으로 평가하였는데 '대단히 좋음' 9점, '대단히 싫어함’ 1점으로 주도록 하였다.

\section{통계 처리}

통계처리는 통계프로그램인 SPSS(12.0K, SPSS Inc, Chicago, IL, USA)를 이용하였고 각 시료를 3회 반복하여 측정한 값을 평균 \pm 표준편차로 나타내었다. 각 처리구간의 통계적 유의성은 one-way ANOVA로 분석하고 $\mathrm{p}<0.05$ 수준 에서 Duncan's multiple range test를 이용하여 유의적 차이 를 검증하였다.

\section{결과 및 고찰}

\section{당도, $\mathrm{pH}$ 및 총산도}

쌀당화액(rice mash)의 첨가량에 따른 딸기잼의 당도, $\mathrm{pH}$ 및 총산도를 측정한 결과는 Table 2 와 같다. Rice mash의 첨가량이 증가할수록 당도는 $65.33 \sim 53.00^{\circ} \mathrm{Brix}$ 의 범위로 유의적으로 낮아졌다(p<0.05). 대조구(SJ0)는 Jung과 Kang (21)의 결과와 유사하였으나 rice mash를 첨가한 처리구 (SJ14, SJ21) 보다는 높았다. 따라서 rice mash를 첨가함으로 써 잼의 당도를 $60^{\circ} \mathrm{Brix}$ 이하로 낮출 수 있음을 확인하였다. $\mathrm{pH}$ 의 경우 rice mash 첨가량이 많아질수록 4.20 4.11로 미 비한 감소를 보였다. Rice mash의 혼합비율을 달리한 딸기
잼의 총산도는 rice mash의 첨가량이 많아질수록 $0.80 \%$ 에 서 $0.66 \%$ 으로 유의적으로 낮아지는 경향이었다 $(\mathrm{p}<0.05)$. 이는 rice koji(Asp. kawachii로 배양한 rice koji)가 쌀전분을 당화과정 중에 유기산을 함유하는 rice mash을 완성하므로 총산도에 영향을 미치는 것이다(22). Kim 등(19)의 당화 딸기죽은 당화액의 첨가량이 증가할수록 총산도는 증가되 는 것으로 보고하였다. 본 연구의 rice mash는 Asp. kawachii 로 배양된 rice koji를 사용한 반면 Kim 등(19)의 당화 딸기 죽에서의 당화액은 Asp. oryzae로 배양된 rice koji로부터 제조한 것을 사용한 원료 차이로 해석되는데 이는 $\mathrm{Kim}$ 등 (20) 결과에서도 같은 원리로 알아 볼 수 있다.

Table 2. Soluble solids, $\mathrm{pH}$ and total acidity of strawberry jam with different levels of added rice mash

\begin{tabular}{cccc}
\hline Sample code ${ }^{1)}$ & $\begin{array}{c}\text { Soluble solids } \\
\left({ }^{\circ} \text { Brix }\right)\end{array}$ & $\mathrm{pH}$ & $\begin{array}{c}\text { Total acidity } \\
(\text { Citric acid, \%) }\end{array}$ \\
\hline SJ0 & $65.33 \pm 0.58^{\mathrm{a} 2)}$ & $4.20 \pm 0.01^{\mathrm{NS} 3)}$ & $0.80 \pm 0.01^{\mathrm{a}}$ \\
SJ14 & $56.67 \pm 0.58^{\mathrm{b}}$ & $4.13 \pm 0.01$ & $0.68 \pm 0.01^{\mathrm{b}}$ \\
SJ21 & $53.00 \pm 0.00^{\mathrm{c}}$ & $4.11 \pm 0.01$ & $0.66 \pm 0.01^{\mathrm{c}}$ \\
\hline
\end{tabular}

${ }^{1)}$ SJ0, strawberry jam added with no rice mash; SJ14, strawberry jam added with rice mash $14 \%$; SJ21, strawberry jam added with rice mash $21 \%$.

${ }^{2)}$ Means with different letters within the same column are significantly different from each other at $\mathrm{p}<0.05$ by Duncan's multiple range test.

${ }^{3)} \mathrm{NS}$, not significant.

\section{색도 측정}

Rice mash의 첨가량에 따른 딸기잼의 색도 측정 결과는 Table 3 과 같다. $\mathrm{L}$, a 및 $\mathrm{b}$ 값의 측정값은 rice mash 첨가량이 증가할수록 모두 증가하는 경향을 보였다 $(\mathrm{p}<0.05) . \mathrm{L}$ 값은 rice mash 첨가수준이 증가할수록 $1.17,5.39,9.41$ 로 유의적 인 차이를 보였고, a값에서도 $7.40,27.43,31.75$ 로 증가되었 고, $\mathrm{b}$ 값도 $1.85,9.14,16.06$ 으로 rice mash 첨가량이 많아질 수록 크게 증가하는 경향이었다. 이는 딸기의 안토시아닌 색소에 황백색의 불투명한 rice mash 첨가량이 증가하면서 $\mathrm{L}$ 값과 $\mathrm{b}$ 값에 영향을 주는 것이다. 이는 $\mathrm{Kim}$ 등(23)의 당화 방울토마토죽의 rice mash의 첨가량이 많아질수록 이와 같 은 경향을 보인 것과 같았고, 그 값의 수준도 비슷하였다.

Table 3. CIE color values of strawberry jam with different levels of added rice mash

\begin{tabular}{cccc}
\hline Sample code $^{1)}$ & \multicolumn{3}{c}{ CIE color values } \\
\cline { 2 - 4 } & $\mathrm{L}$ & $\mathrm{a}$ & $\mathrm{b}$ \\
\hline SJ0 & $1.17 \pm 0.03^{\mathrm{c} 2)}$ & $7.40 \pm 0.21^{\mathrm{c}}$ & $1.85 \pm 0.06^{\mathrm{c}}$ \\
SJ14 & $5.39 \pm 0.36^{\mathrm{b}}$ & $27.43 \pm 0.74^{\mathrm{b}}$ & $9.14 \pm 0.61^{\mathrm{b}}$ \\
SJ21 & $9.41 \pm 0.05^{\mathrm{a}}$ & $31.75 \pm 0.21^{\mathrm{a}}$ & $16.06 \pm 0.10^{\mathrm{a}}$ \\
\hline
\end{tabular}

${ }^{1)}$ SJ0, strawberry jam added with no rice mash; SJ14, strawberry jam added with rice mash 14\%; SJ21, strawberry jam added with rice mash $21 \%$.

${ }^{2}$ Means with different letters within the same column are significantly different from each other at $\mathrm{p}<0.05$ by Duncan's multiple range test. 


\section{유리당 함량 측정}

Rice mash의 첨가량에 따른 딸기잼의 유리당 함량은 Table 4와 같다. 검출된 유리당은 fructose, glucose, sucrose 및 maltose였고 각 처리구별 결과 값은 모두 유의적인 차이 를 보였다(p<0.05). Rice mash를 첨가하지 않은 대조구(SJ0) 는 sucrose 함량이 $40.22 \mathrm{~g} / 100 \mathrm{~g}$ 으로 rice mash를 첨가한 시료(SJ14, SJ21) 보다 유의적으로 가장 높았고( $\mathrm{p}<0.05)$, fructose, glucose 및 maltose 함량은 각각 4.11, 3.86 및 4.24 $\mathrm{g} / 100 \mathrm{~g}$ 을 보였다. 반면 rice mash를 $14 \%$ 첨가한 처리구 (SJ14)는 fructose, glucose, sucrose, maltose 함량이 각각 $3.14,3.94,33.99,3.87 \mathrm{~g} / 100 \mathrm{~g}$ 이었고, rice mash를 $21 \%$ 첨가 한 처리구(SJ21)에서는 $2.96,4.13,30.48$ 및 $3.73 \mathrm{~g} / 100 \mathrm{~g}$ 으로 나타났다. Fructose, sucrose, maltose의 각각의 함량은 rice mash 첨가량이 증가할수록 전반적으로 감소한 반면 glucose 함량은 유의적으로 증가하였다 $(\mathrm{p}<0.05)$. Kim 등 (20)은 rice mash의 양이 많아질수록 glucose 비율이 유의적 으로 높아졌다고 보고하였는데 본 결과와 유사한 경향이었 다.

Table 4. Free sugar contents of strawberry jam with different levels of added rice mash

\begin{tabular}{ccccc}
\hline \multirow{2}{*}{ Sample code $^{1)}$} & \multicolumn{4}{c}{ Free sugar content $(\mathrm{g} / 100 \mathrm{~g})$} \\
\cline { 2 - 5 } & Fructose & Glucose & Sucrose & Maltose \\
\hline SJ0 & $4.11 \pm 0.03^{\mathrm{a} 2)}$ & $3.86 \pm 0.03^{\mathrm{c}}$ & $40.22 \pm 0.11^{\mathrm{a}}$ & $4.24 \pm 0.06^{\mathrm{a}}$ \\
SJ14 & $3.14 \pm 0.05^{\mathrm{b}}$ & $3.94 \pm 0.03^{\mathrm{b}}$ & $33.99 \pm 0.22^{\mathrm{b}}$ & $3.87 \pm 0.07^{\mathrm{b}}$ \\
SJ21 & $2.96 \pm 0.02^{\mathrm{c}}$ & $4.13 \pm 0.02^{\mathrm{a}}$ & $30.48 \pm 0.18^{\mathrm{c}}$ & $3.73 \pm 0.04^{\mathrm{c}}$ \\
\hline
\end{tabular}

${ }^{1)} \mathrm{SJ} 0$, strawberry jam added with no rice mash; SJ14, strawberry jam added with rice mash 14\%; SJ21, strawberry jam added with rice mash $21 \%$.

${ }^{2}$ Means with different letters within the same column are significantly different from each other at $p<0.05$ by Duncan's multiple range test.

\section{유기산 함량 측정}

Rice mash의 첨가량에 따른 유기산 함량 측정 결과는 Table 5와 같다. 주로 검출된 유기산은 citric acid, malic acid 및 succinic acid였고, citric acid가 가장 높은 함량을 차지하였으며 oxalic acid는 소량 검출되었는데 rice mash를 첨가하지 않은 대조구(SJ0)에서는 검출되지 않았다. 이때 oxalic acid 함량은 당화액을 $14 \%$ 첨가한 처리구(SJ14)와 $21 \%$ 첨가한 처리구(SJ21)에서는 각각 $3.60,5.07 \mathrm{mg}$ 이었다. $\mathrm{Kim}$ 등(4)의 연구에서는 딸기 첨가량에 따른 딸기잼의 oxalic acid 함량은 딸기 첨가수준이 높아질수록 oxalic acid 함량은 증가한다고 보고하였다. 다만 본 연구의 대조구 (SJ0)인 딸기잼에서는 oxalic acid가 검출되지 않았지만 rice mash를 첨가함으로써 oxalic acid 함량이 높아진 것으로 보인다. Citric acid는 그 첨가수준에 따라 감소하는 경향이 었는데 그 함량은 750 661 mg이었고, malic acid는 대조구 (SJ0)에서 633.60, 21\% 첨가 처리구(SJ21)에서는 $448.73 \mathrm{mg}$ 이었다. Succinic acid는 당화액 첨가량이 많아질수록
230.40 348 mg으로 유의적으로 증가하였고( $\mathrm{p}<0.05)$, 이는 $\mathrm{Kim}$ 등(20)의 결과와 유사하였다. 잼의 기호도에 관계될 수 있는 적절한 신맛을 간접적으로 표현해주는 유기산의 총함량은 대조구와 비교할 때 rice mash 첨가 $(14 \% 21 \%)$ 잼의 경우 낮아지는 것으로 나타났으므로 이에 대한 유기산 보충을 위한 보완 실험이 관능검사와 관련하여 보완실험이 이루어져야 할 것으로 보인다.

Table 5. Organic acid contents of strawberry jam with different levels of added rice mash

\begin{tabular}{ccccc}
\hline \multirow{2}{*}{$\begin{array}{c}\text { Sample } \\
\text { code }^{1}\end{array}$} & \multicolumn{4}{c}{ Organic acid content $(\mathrm{mg} / 100 \mathrm{~g})$} \\
\cline { 2 - 5 } & Oxalic acid & Citric acid & Malic acid & Succinic acid \\
\hline SJ0 & $\mathrm{ND}^{2)}$ & $750.30 \pm 3.03^{\mathrm{a3})}$ & $633.60 \pm 2.72^{\mathrm{a}}$ & $230.40 \pm 1.12^{\mathrm{c}}$ \\
SJ14 & $3.60 \pm 0.75^{\mathrm{a}}$ & $690.63 \pm 1.59^{\mathrm{b}}$ & $381.43 \pm 2.30^{\mathrm{b}}$ & $328.80 \pm 3.04^{\mathrm{b}}$ \\
SJ21 & $5.07 \pm 2.20^{\mathrm{a}}$ & $661.30 \pm 4.13^{\mathrm{c}}$ & $448.73 \pm 87.10^{\mathrm{b}}$ & $348.00 \pm 1.90^{\mathrm{a}}$ \\
\hline
\end{tabular}

${ }^{1)} \mathrm{SJ} 0$, strawberty jam added with no rice mash; SJ14, strawberry jam added with rice mash 14\%; SJ21, strawberry jam added with no rice mash $21 \%$.

${ }^{2)} \mathrm{ND}$, not detected.

${ }^{3)}$ Means with different letters within the same column are significantly different from each other at $p<0.05$ by Duncan's multiple range test.

\section{관능검사}

Rice mash의 첨가량에 따른 딸기잼의 관능검사 결과는 Table 6과 같다. 색과 맛의 특성 항목에 있어서는 설탕 첨가 수준을 30\% 수준으로 하여 rice mash $14 \%$ (SJ14)와 21\% 첨가한 처리구(SJ21)간에는 서로 유의적인 차이가 없었으 나 당화액을 첨가하지 않은 대조구를 더 선호하는 것으로 나타났다. 반면 잼을 식빵에 발라 먹을 때 중요한 딸기향 냄새, 질감의 특성 항목은 대조구(SJ0)와 rice mash $14 \%$, $21 \%$ 첨가 처리구(SJ14, SJ21) 간에는 서로 유의적 차이가 없었다. 잼의 식빵의 스프레드 정도에 관한 항목에 있어서 는 rice mash 첨가 처리구(SJ14, SJ21)가 대조구보다 모두 선호하는 것으로 나타났는데 $(\mathrm{p}<0.05)$ 이는 rice mash의 농 도에 의한 영향으로 해석된다. 전반적 기호도는 대조구 (SJO)와 rice mash $14 \%$ 첨가 처리구(SJ14)와는 유의적 차이

Table 6. Sensory evaluation of strawberry jam with different levels of added rice mash

\begin{tabular}{ccccccc}
\hline $\begin{array}{c}\text { Sample } \\
\text { code }\end{array}$ & Color & Flavor & Taste & Texture & Spread & $\begin{array}{c}\text { Overall } \\
\text { acceptability }\end{array}$ \\
\hline SJ0 & $6.5 \pm 1.0^{\mathrm{a} 2)}$ & $7.1 \pm 1.3^{\mathrm{NS} 33}$ & $7.2 \pm 0.9^{\mathrm{a}}$ & $6.3 \pm 1.3^{\mathrm{NS}}$ & $5.6 \pm 2.0^{\mathrm{b}}$ & $6.8 \pm 0.8^{\mathrm{a}}$ \\
SJ14 & $5.2 \pm 1.2^{\mathrm{b}}$ & $6.1 \pm 1.3$ & $6.2 \pm 1.1^{\mathrm{b}}$ & $5.8 \pm 1.1$ & $7.2 \pm 1.1^{\mathrm{a}}$ & $6.3 \pm 1.0^{\mathrm{ab}}$ \\
SJ21 & $4.5 \pm 1.1^{\mathrm{b}}$ & $6.2 \pm 1.0$ & $5.7 \pm 1.4^{\mathrm{b}}$ & $5.8 \pm 1.2$ & $7.0 \pm 0.9^{\mathrm{a}}$ & $5.5 \pm 1.0^{\mathrm{b}}$ \\
\hline
\end{tabular}

${ }^{1)} \mathrm{SJ}$, strawberry jam added with no rice mash; SJ14, strawberry jam added with rice mash 14\%; SJ21, strawberry jam added with rice mash $21 \%$.

${ }^{2}$ Means with different letters within the same column are significantly different from each other at $p<0.05$ by Duncan's multiple range test.

${ }^{3} \mathrm{NS}$, not significant. 
를 없었지만, $21 \%$ 첨가 처리구(SJ21)와는 유의적 차이를 보였다. 이상의 관능검사 결과로부터 기존의 설탕잼에 익 숙하여 rice mash를 첨가하지 않은 대조구(SJ0)에서 색, 맛 특성 항목에서 높은 점수를 보이는 경향이었고 스프레드 정도에서는 rice mash 첨가 처리구(SJ14, SJ21) 모두 좋았다. 전반적 기호도에서는 대조구와 rice mash $14 \%$ 처리구가 우수하였으므로 rice mash를 잼의 제조 원료로서 이용가능 성을 확인할 수 있었다. 하지만 rice mash 원료 자체가 지닌 색으로 인한 잼의 색상과 과실향을 낮출 수 있어 과실첨가 등의 보완 실험이 필요하다고 본다.

\section{요 약}

본 연구에서는 쌀과 쌀누룩(rice koji)을 이용하여 당화과 정을 거쳐 생성된 쌀당화액(rice mash)은 당도와 유기산을 가진 잼 제조의 원료로 활용하고자 딸기와 설탕의 첨가 수준 대비 rice mash 첨가량을 $0 \%, 14 \%, 21 \%$ 로 달리하여 제조한 딸기잼의 이화학적 및 관능적 특성을 조사하였다. Rice mash 첨가량이 증가할수록 딸기잼의 당도 및 총산도 는 유의적으로 낮아지는 경향이었다 $(\mathrm{p}<0.05)$. 색도는 rice mash 첨가수준이 증가할수록 $\mathrm{L}, \mathrm{a}$ 및 $\mathrm{b}$ 값 모두 증가하였다. 또한 딸기잼의 유리당으로 fructose, glucose, sucrose 및 maltose가 검출되었으며, glucose 함량은 rice mash 첨가량 이 증가할수록 $3.86 ~ 4.13 \mathrm{~g}$ 으로 증가된 반면 fructose, sucrose 및 maltose 함량은 이와 다르게 감소되었다 $(\mathrm{p}<0.05)$. 처리구에서 검출된 유기산은 oxalic acid, citric acid, malic acid 및 succinic acid였으며, oxalic acid는 대조구에서는 검 출되지 않았다. Succinic acid는 당화액 첨가수준이 많아질 수록 증가하였다 $(\mathrm{p}<0.05)$. Rice mash 첨가량에 따른 딸기잼 의 관능검사 결과 색, 맛 항목에서는 rice mash를 첨가하지 않은 대조구를 가장 선호하는 것으로 나타났다. 냄새, 질감 (texture), 스프레드(spread)의 경우에는 모든 처리구간에 유 의적 차이를 보이지 않았다. 전반적 기호도는 기존의 설탕 잼의 단맛에 익숙하여 rice mash를 첨가하지 않은 대조구가 점수가 높았지만 rice mash $14 \%$ 첨가 처리구(SJ14)와는 유 의적인 차이를 보이지 않았다. 이상의 결과를 종합해 볼 때 당과 산을 생성하는 rice mash를 설탕 대체 또는 산 조절 제로 이용하여 기존 잼의 당도를 낮추며 품질을 높일 수 있을 것으로 기대되는 바, 건강지향 요구에 따른 새로운 잼 제품을 개발하는데 유용한 정보로 사용될 수 있을 것으 로 보인다.

\section{감사의 글}

본 연구는 국립농업과학원 농업과학기술 연구개발사업
(과제번호 PJ008661)에 의해 이루어진 것으로 감사드립니 다.

\section{References}

1. Jeong EJ, Kim MH, Kim YS (2010) Effect of pectinase treatment on extraction yield of the juice of Fragaria ananassa Duch. and the quality characteristics of strawberry wine during ethanolic fermentation. Korean J Food Preserv, 17, 72-78

2. Kim MY, Chun SS (2001) Effects of onion on the quality characteristics of strawberry jam. Korean J Food Cookery Sci, 17, 316-322

3. Kim YA (2008) Effects of strawberry powders on the quality characteristics of yellow layer cake. Korean J Food Cookery Sci, 24, 536-541

4. Kim JS, Kang EJ, Chang YE, Lee JH, Kim GC, Kim KM (2013) Characteristics of strawberry jam containing strawberry puree. Korean J Food Cookery Sci, 29, 725-731

5. Lee EY, Jang MS (2009) Optimization of ingredients for the preparation of Chinese quince (Chaenomelis sinensis) jam by mixture design. Korean J Soc Food Sci Nutr, 38, 935-945

6. KFDA (2015) Korea food standard code. Korea Food and Drug administration, Korea, 4, 54-55

7. Lee GD, Jeong YJ (1999) Optimization on organoleptic properties of red pepper jam by response surface methodology. Korean J Soc Food Sci Nutr, 28, 1269-1274

8. Park MJ (2013) Physicochemical characteristics of cheonnuyncho fruit (Opuntia humifusa) fermented by lactic acid bacteria and the manufacture of jam. MS Thesis. Keimyung University, Korea, p 1-3

9. Hwang ES, Nhuan DT (2014) Quality characteristics and antioxidant activities of aronia jam replacing sucrose with different sugar substances. Korean J Food Nutr, 27, 888-896

10. Hou WN, Kim MH (1998) Processing of low sugar jams from fig pulp treated with pectinesterase. Korean J Food Sci Technol, 30, 125-131

11. Kim MJ, Yoon SH, Jung MY, Choe EO (2008) Effects of sugars and pectin on the quality characteristics of low sugar wild vine (Vitis coignetiea) jam. Korean J Food Cookery Sci, 24, 206-211

12. Sim KH, Joo NM, Han YS (2006) Optimization of garlic jam making by response surface methodology. Korean 
J Dietetic Association, 12, 32-43

13. Park HM, Kwak HS, Kim SH, Moon MA, Oh MJ (2008) Changes in quality characteristics of garlic jam during storage. Korea J Agri Sci, 35, 183-191

14. Kim MH, Kim MH, Yun SJ, Lee BY, Lee CW, Kim BA, Jang KH, Lee JC, Surh JH (2010) Preparation and quality characterization of apple jam with Rosa rugosa Thunb. fruit. Korean J Food Cookery Sci, 26, 367-380

15. Cho WJ, Song BS, Lee JY, Kim JK, Kim JH, Yoon YH, Choi JI, Kim GS, Lee JW (2010) Composition analysis of various blueberries produced in Korea and manufacture of blueberry jam by response surface methodology. Korean J Soc Food Sci Nutr, 39, 319-323

16. Jin TY, Heo SI, Lee WG, Lee IS, Wang MH (2008) Manufacturing characteristics and physicochemical component analysis of bokbunja (Rubus coreanus Miquel) jam. Korean J Soc Food Sci Nutr, 37, 48-52

17. Kim MJ, Kim MH, Kim HJ, Lee JY, Kim HR, You BR, Yang KH, Kim MR (2010) Antioxidant activities and quality characteristics of black garlic jam containing maltitol substituted for sucrose. Korean J Food Cookery Sci, 26, 866-871

18. So MH (1991) Improvement in the quality of takju by the combined use of Aspergillus kawachii and Aspergillus oryzae. Korean J Food Nutr, 4, 115-124

19. Kim JS, Kim JY, Chang YE (2012) The quality characteristic and antioxidant properties of saccharified strawberry gruels. Korean J Soc Food Sci Nutr, 41, 752-758

20. Kim JS, Lee JH, Chang YE, Kim GC, Kim KM (2013) The quality characteristics of rice mash by mixing ratios of rice and rice koji. Korean J Soc Food Sci Nutr, 42, 2035-2041

21. Jung NJ, Kang YH (2012) Comparison of the physicochemical quality characteristics of strawberry jams by processing methods. Korean J Food preserv, 19, 337-343

22. Hwang IG, Yang JW, Kim JY, Yoo SM, Kim GC, Kim JS (2011) Quality characteristics of saccharified rice gruel prepared with different cereal koji. Korean J Soc Food Sci Nutr, 40, 1617-1622

23. Kim JS, Kim JY, Yang JW (2011) The quality characteristics of saccharified cherry tomato gruel prepared with rice mash. Korean J Food Cookery Sci, $27,755-762$ 